\title{
Diabetes knowledge, medication adherence, and glycemic control among diabetic patients: A cross-sectional study in Jordan
}

\author{
Saba Madae'en ${ }^{*}$, Eman Elayeh ${ }^{1}$, Amal Akour $^{1}$, Tahanie AlQhaiwi², Bayan Shaggour ${ }^{1}$, Rola Madain ${ }^{3}$ \\ ${ }^{1}$ Department of Biopharmaceutical and Clinical Pharmacy, School of Pharmacy, The University of Jordan, Amman, Jordan. \\ ${ }^{2}$ Royal Medical Services RMS, Amman, Jordan. \\ ${ }^{3}$ School of Medicine, The University of Science and Technology, Irbid, Jordan.
}

\begin{tabular}{l}
\hline ARTICLE INFO \\
\hline Received on: 22/05/2019 \\
Accepted on: 13/09/2019 \\
Available online: 04/04/2020 \\
\\
\hline Key words: \\
Diabetes, glycemic control, \\
medication adherence, \\
diabetes knowledge.
\end{tabular}

\section{INTRODUCTION}

Diabetes mellitus (DM) is an issue of focus worldwide not only because of its alarming increase but also because of its consequences on general health and correlation with other medical problems. The number of patients suffering from DM in 2017 was found to be 425 million and the number is expected to increase to reach an estimate of 629 million by the year 2045 (International diabetes Federation 2017; Wild et al., 2004).

According to the figures derived from the National Centre for diabetes, endocrinology and genetics in Jordan, the prevalence of type $2 \mathrm{DM}$ in adults aged 25 years and above demonstrating a significant increase throughout the years 1998-2017 and its prevalence in 1998 was $13.4 \%$ to only increase in 2008 to $17.1 \%$ (Ajlouni et al., 2008). In 2017, the prevalence of DM was 28.3\%

\section{*Corresponding Author}

Saba Madae'en, Department of Biopharmaceutical and clinical pharmacy, School of Pharmacy, The University of Jordan, Amman, Jordan.

E-mail: s.madain@ju.edu.jo
(95\% CI: 25.5, 31.1) among males and 19.9\% (95\% CI: 18.1, 21.6) among females in a study by Zerriouh and Khader (2018). The previous studies confirm that the prevalence of diabetes is increasing in Jordan.

Uncontrolled DM leads to complications such as heart disease, stroke, hypertension, blindness, nephropathy, neuropathy, amputations of legs, and premature death (Sratton et al., 2000). And since DM is a chronic disease that is associated with serious complications, causing patients and their families to adopt a new lifestyle (Coffey et al., 2002). This all explains that the average medical cost of diabetic patients is 2.3 times higher than people without diabetes as estimated by the American Diabetes Association. As it caused 727 billion dollars in health expenditure in 2017 in the united states (International Diabetes Federation, 2017).

Findings from the Behavioral Risk Factors Surveillance System which was conducted in 2004 by CDC revealed that the burden of non-communicable diseases, diabetes being a major one of those diseases, in Jordan is very high and diabetes as a chronic disease is one of the leading causes of morbidity and mortality in Jordan (Zindah et al., 2004). Knowing that DM is considered a 
major risk factor for cardiovascular disease (Jaffe et al., 2006), Worldwide, cardiovascular diseases are the leading causes of death (Brown et al., 2009; International Diabetes Federation, 2006).

Many studies investigated the extent of diabetes knowledge among diabetic patients and its effect on medication adherence, and therefore glycemic control. The sub-optimal level of knowledge was acknowledged in several studies of many countries (Angeles et al., 2005; Al Shafaee et al., 2008; Bruce et al., 2003; Gunay et al., 2006; Murata et al., 2003; McClean et al., 2001; Murugesan et al., 2007). Diabetes self-management and education have a vital role in improving diabetes outcomes as shown by Funnell et al. (2007), furthermore literature showed that increased diabetes knowledge is associated with greater glycemic control (Berikai et al., 2007; Hartz et al., 2006; Norris et al., 2002; Panja et al., 2005). Results from different studies show that diabetic patients with good adherence to medications had positive health outcomes and lower mortality compared to those with poor adherence (Krapek et al., 2004; Rhee et al., 2005; Simpson et al., 2006) and that adherence to diabetes medications is considered substandard (Briesacher et al., 2008). The assessment of glucose control by hemoglobin Alc (HbAlc) is the standard practice (American Diabetes Association, 2010; Krapek et al., 2004; Tesfaye et al., 2005). Achieving lower HbA1c levels is well-known to be associated with decreased mortality and fewer complications (Hirai et al., 2008; Ishimura et al., 2009; Jacobsen et al., 2008; Siddiqui et al., 2008; Tka'c, 2009).

It is always recommended to increase the educational programs for diabetics. However, none of the previously published studies demonstrated the effect of the knowledge on adherence and hence HbAlc control. Therefore, in our study, we show the effect to better clarify the problem to help evaluate the solution proposed.

Our study purpose was derived from the lack of data regarding the relationship between both the knowledge in diabetic patients and their adherence score with glycemic control. The target from the study was first: to assess the knowledge level among Jordanians with type 2 diabetes and its correlation with socio-demographic variables. Second: to assess the adherence and its correlation with sociodemographic variables, and finally: the correlation between both scores of knowledge and adherence with glycemic control.

\section{METHODS}

\section{Participants and setting}

This was a cross-sectional study which we carried out on patients who were treated in the Endocrine Clinic of Jordan University Hospital (JUH). The number of patients registered in the clinic at time of study was 10,600 , and according to sample size calculation using the online calculator (Raosoft sample size calculator: (http://www.raosoft.com/samplesize.html), the sample size was 400 and we increased it to 600 to enhance the accuracy of our results; therefore, we recruited 521 type 2 diabetic patients that visited the clinic in the period from September 2012 to June 2013.

The inclusion criteria were (1) Adult ( $\geq 18$ years of age) patients diagnosed with type 2 DM, (2) Patients treated for DM with oral medications or insulin, (3) the differentiation ability between each medication and its indication, and (4) the verbal consent from the patient himself. Exclusion criteria were the ability of the patient to answer independently without help from staff or family members.

Data collection was done by face-to-face patient interview by trained Pharm D students. (HbAlc) levels were taken from (JUH) documented medical records for the previous 6 months and anti-diabetic medication numbers were taken from the hospital pharmacy records.

\section{Data collection form}

Data were collected using two previously validated questionnaires among patients with diabetes type 2 who attended the Endocrine Outpatient Clinic at Jordan University Hospital. The questionnaire consisted of three main parts: (1) sociodemographic and diabetes-related data including glycemic control parameters, (2) general diabetes knowledge of the patients, and (3) medication adherence.

\section{Diabetes knowledge}

We used the Michigan diabetes knowledge test (MDKT) that was developed by The Michigan Diabetes Research and Training Center to assess the general knowledge of diabetes (Fitzgerald et al., 1998).

The MDKT was translated into the Arabic language and piloted to patients. The general MDKT consists of 23 multiple choice questions. The score is calculated giving 1 point for each correct answer, the higher the score the better the knowledge in diabetes in general.

\section{Medication adherence}

Morisky Medication Adherence Scale (MMAS) was used for the assessment of medication adherence (Morisky et al., 2008). The MMAS was translated into the Arabic language and tested for validity and reliability.

MMAS score is calculated by giving a point for each correct yes or no question while multiple-choice question, that is question number 8 has one point for all its five choices. The score is out of 8 , the higher the number the lower the adherence. The MMAS score is validated and the correlation was proven between the score and the number of tablets dispensed for each patient at a rate of 75\% (Krousel-Wood et al., 2009).

\section{Glycemic control}

The study defined good glycemic control by HbAlc lower than $7 \%$ according to the American Diabetic Association since it correlates to blood glucose levels in the prior 3 months(Gonen et al., 1977; Sacks et al., 2002).

\section{Statistical analysis}

Data collected were transferred on SPSS program version 16.0, the analysis was done for the demographic and disease data according to the type of the data, if it is categorical or normally distributed, descriptive analysis shows frequencies and percentages or average and standard deviation. While for testing the differences of knowledge score as well as adherence score between groups, Mann-Whitney test and Kruskal-Wallis test were used.

Bonferroni post hoc procedure was applied if differences were found while using the Kruskal-Wallis test. Last, 
the correlation of both scores with $\mathrm{HbAlc}$ was tested using the Spearman correlation coefficient.

Multivariate binary logistic regression analysis and adjusted odds ratios were used to identify factors associated with good glycemic control. The significance level was set at $p$ value less than 0.05 (Mickey and Greenland, 1989).

\section{RESULTS}

The total number of patients included in this study was 464,142 of which counting for $23 \%$ of the study population, were excluded for having missing data either HbA1c $(n=85)$ or lack of information $(n=57)$. Fifty-three patients refused to participate in the study.

\section{Demographic and clinical characteristics}

The demographic data for participants were sorted in Table 1, using the frequency distribution of the study patients and disease-related data. The mean age of the patients was 57.9 years $(\mathrm{SD}=10.89)$, ranging from 19 to 85 years, with $53.4 \%$ females. The mean duration of diabetes was 8.4 years $(\mathrm{SD}=6.2)$. The majority of patients were on monotherapy of oral anti-diabetes medications and did not use insulin for their diabetes management

\section{Patients' knowledge}

The median score was $13(\mathrm{IQR}, 4)$. As shown in Table 1, no significant difference in MDKT scores was found between different groups of the patients except between genders. The best knowledge score was shown in patients with age younger than 45 and it was correlated with a median adherence score of 5 which happens to be the highest adherence score between all ages. No significant correlation was shown between knowledge and adherence across all ages. And knowledge median was 14 in full-time employed and unemployed which was higher than those with part-time job.

Table 1. Demographic and disease characteristics of the diabetic patients with differences in knowledge and adherence total scores $(N=322)$.

\begin{tabular}{|c|c|c|c|c|c|c|c|}
\hline \multirow{2}{*}{ Variables } & \multirow{2}{*}{ Frequency (\%) } & \multicolumn{2}{|c|}{ MDKT } & \multicolumn{2}{|c|}{ MMAS } & \multicolumn{2}{|c|}{ HbA1C } \\
\hline & & Median (IQR) & $p$ & Median (IQR) & $p$ & Median (IQR) & $p$ \\
\hline Age $^{*}$ & & & 0.347 & & 0.656 & & 0.347 \\
\hline$<45$ & $33(10.4)$ & $14(3.75)$ & & $5(2.5)$ & & $7.55(1.0)$ & \\
\hline $45-54$ & $65(20.4)$ & $13(5)$ & & $6(3)$ & & $7.5(1.0)$ & \\
\hline $55-64$ & $119(37.4)$ & $13(4)$ & & $5(3)$ & & $7.5(1.5)$ & \\
\hline$\geq 65$ & $101(31.8)$ & $13(2)$ & & $6(3)$ & & $7.8(1.0)$ & \\
\hline Gender $^{* * *}$ & & & 0.03 & & 0.570 & & 0.237 \\
\hline Male & $150(46.6)$ & $13(3)$ & & $6(3)$ & & $7.5(1.12)$ & \\
\hline Female & $172(53.4)$ & $13(4)$ & & $5(3)$ & & $7.5(1.00)$ & \\
\hline Education" & & & 0.294 & & 0.786 & & 0.294 \\
\hline Primary & $145(47.1)$ & $13(4)$ & & $6(3)$ & & $7.5(1.5)$ & \\
\hline Secondary & $54(17.5)$ & $13(3)$ & & $6(3.25)$ & & $7.5(1.0)$ & \\
\hline $\begin{array}{l}\text { Some college or technical } \\
\text { school }\end{array}$ & $37(12)$ & $13(5.5)$ & & $6(3)$ & & $7.5(1.5)$ & \\
\hline University & $72(23.4)$ & $13(3)$ & & $5(3)$ & & $7.3(1.1)$ & \\
\hline Employment ${ }^{*}$ & & & 0.135 & & 0.135 & & 0.135 \\
\hline Full time & $45(14)$ & $14(4)$ & & $6(3)$ & & $7.2(1.1)$ & \\
\hline Part time & $29(9)$ & $13(2.5)$ & & $6(4)$ & & $7.5(1.3)$ & \\
\hline Unemployed & $20(6.3)$ & $14.5(5.5)$ & & $5.5(3.75)$ & & $7.5(2.4)$ & \\
\hline Homemaker & $145(45.2)$ & $13(4)$ & & $5(3)$ & & $7.5(1.35)$ & \\
\hline Retired & $75(23.4)$ & $13(3)$ & & $6(3)$ & & $7.6(0.8)$ & \\
\hline Others & $8(2.1)$ & $13(3)$ & & $6(1.0)$ & & $6.75(1.67)$ & \\
\hline Income ${ }^{* *}$ & Missing 5 & & 0.112 & & 0.003 & & 0.798 \\
\hline$>500 \mathrm{JD}$ & $196(61.8)$ & $13(4)$ & & $5(3.5)$ & & $7.5(1.00)$ & \\
\hline$<500 \mathrm{JD}$ & $121(38.2)$ & $13(3)$ & & $6(3)$ & & $7.6(1.3)$ & \\
\hline Diabetes duration" & & & 0.383 & & 0.883 & & 0.383 \\
\hline$<5$ years & $111(34.5)$ & $13(3.75)$ & & $5.5(3)$ & & $7.5(1.05)$ & \\
\hline $5-9$ years & $92(28.6)$ & $13(4)$ & & $6(4.0)$ & & $7.5(1.0)$ & \\
\hline $10-14$ years & $91(28.3)$ & $13(3)$ & & $5(3)$ & & $8(1.5)$ & \\
\hline$\geq 15$ years & $28(8.6)$ & $13(6)$ & & $5.5(3.25)$ & & $8(2.15)$ & \\
\hline Medication number ${ }^{\text {t*t }}$ & & & 0.137 & & 0.804 & & 0.06 \\
\hline Mono-therapy & $175(54.3)$ & $13(2.5)$ & & $6(3)$ & & $7.5(1.0)$ & \\
\hline Multi-therapy & $147(45.7)$ & $13(4)$ & & $6(3)$ & & $7.8(1.5)$ & \\
\hline
\end{tabular}

*Kruskal-Wallis test, **Mann-Whitney U test. 


\section{Medication adherence}

The median was 6 (IQR, 3). A significant difference in MMAS scores was found between low- and high-income individuals, as those patients with higher income ( $>500$ JD) had lower medication adherence. Patients taking mono or multitherapy did not have different MMAS scores, as shown in Table 1.

Comparing the MDKT scores and MMAS scores between the two groups of glycemic control, there was no significant difference in scores of both MDKT and MMAS in the good glycemic control group comparing to those with a poor glycemic control group $(p>0.05)$ as shown in Table 2 .

\section{Glycemic control}

Demonstrated in Table 3, glycemic control was studied with several variables. Two of which were statistically significant with glycemic control, "Measure blood glucose as recommended" $(p=0.007)$, and "Check feet" $(p=0.006)$. Table 3 shows that the two lifestyle activities that are practiced by the highest percent of patients each day are washing their feet everyday $90.4 \%$ of patients, and checking their feet $74.7 \%$ of patients, while all other daily lifestyle activities were practiced by less than $50 \%$ of patients every day.

\section{DISCUSSION}

The aim of this study was to assess the knowledge and adherence of Jordanian diabetic patients, evaluate the relationship between their knowledge, adherence, and $\mathrm{HbA1C}$ and lastly to explore if there are any factors that could influence their knowledge or adherence and subsequently their $\mathrm{HbA} 1 \mathrm{C}$ as age, gender, marital status, income, number of medications, and insulin use. We hypothesized that the knowledge significantly effects the adherence and consecutively the HbAlc. Interestingly, our results did not support the hypothesis.

Table 2. Differences in knowledge scores and medication adherence scores between two groups of glycemic control.

\begin{tabular}{lccccc}
\hline \multirow{2}{*}{ Variables } & $\begin{array}{c}\text { Frequency } \\
(\%)\end{array}$ & MKDT & $\boldsymbol{p}$ value & MMAS & $\boldsymbol{p}$ value \\
\cline { 3 - 6 } & & Median (IQR) & $\mathbf{0 . 1 4 6}$ & Median (IQR) & $\mathbf{0 . 9 9 4}$ \\
\hline Good $(\leq 7 \%)$ & $105(32.6)$ & $13(3)$ & & $5(3.0)$ & \\
Poor $(>7 \%)$ & $217(67.4)$ & $13(4)$ & & $6(3.0)$ & \\
\hline
\end{tabular}

Table 3. Frequencies and percentages of performance of self-care practices among patients with diabetes $(n=)$ Frequency (Days per week) $n(\%)$.

\begin{tabular}{|c|c|c|c|c|}
\hline Variable & $\mathbf{0}$ & 1-3 & $4-6$ & 7 \\
\hline Follow healthy diet & $92(29.6)$ & $58(18.6)$ & $66(21.2)$ & $95(30.5)$ \\
\hline $\begin{array}{l}\text { Consume } 2-3 \text { servings or more } \\
\text { of fruit }\end{array}$ & $10(3.2)$ & $101(32.3)$ & $82(26.2)$ & $120(38.3)$ \\
\hline Consume diet rich in fat & $48(15.3)$ & $182(58.0)$ & $59(18.8)$ & $25(8.0)$ \\
\hline $\begin{array}{l}\text { Participate in specific physical } \\
\text { sport cycle }\end{array}$ & $254(82.2)$ & $36(11.7)$ & $9(2.9)$ & $10(3.2)$ \\
\hline $\begin{array}{l}\text { Measure blood glucose as } \\
\text { recommended }\end{array}$ & $60(19.3)$ & $95(30.5)$ & $29(9.3)$ & $127(40.8)$ \\
\hline $\begin{array}{l}\text { Consume } 5 \text { servings or more of } \\
\text { vegetables }\end{array}$ & $14(4.5)$ & $82(26.3)$ & $85(27.2)$ & $131(42)$ \\
\hline Exercise for at least 30 minutes & $158(50.6)$ & $77(24.7)$ & $29(9.3)$ & $48(15.4)$ \\
\hline Inspect inside shoes & $120(38.8)$ & $26(8.40$ & $21(6.8)$ & $142(46.0)$ \\
\hline Check feet & $41(13.1)$ & $19(6.1)$ & $19(6.1)$ & $233(74.7)$ \\
\hline Wash feet & $9(2.8)$ & $9(2.8)$ & $12(3.9)$ & $281(90.4)$ \\
\hline
\end{tabular}

Our interest in diabetes is rooted from the fact that there is a high prevalence of diabetes and pre-diabetes in Jordan with the percentages of $17.1 \%, 7.8 \%$, respectively, according to the agestandardized prevalence rate (Ajlouni et al., 2008).

In 2019, an article for Alsous et al. (2018) showed the knowledge scores for diabetic patients in Jordan was low, where only $53.3 \%$ of patients had good knowledge scores. While the recommendation of this study was to increase the educational interventions, another study done by El-Qudah (2016) explored the knowledge in diabetic females in Jordan and assessed the effect of education on glycemic control. The later study showed that more than $56.1 \%$ did not know daily meal recommendations and those studies agree with our results.

A study conducted in 2017 by Zerriouh and Khader showed that two-thirds of diabetics enrolled in the study had unsatisfactory blood glucose control (Zerriouh and Khader, 2018) their recommendation was to increase the programs to encourage optimum diabetes behavior.

Therefore, it is essential to reevaluate the need of knowledge level to emphasize on the imminent need for educational programs and to the extent of benefit of such programs in increasing knowledge and subsequently improving adherence and lifestyle management resulting in better diabetic control and less overall cost from the disease and its complications.

The data of our study showed that the knowledge score according to MDKT score was $13,56.52 \%$ which is lower than that reported in other studies such as Al-Qazaz et al. (2011), which was conducted in Malaysia with a score of 7.0 (5-10). Other studies reported a low level of diabetes knowledge such as; poor performance on the diabetes knowledge test $(64.9+/-15.3 \%$ correct) in Murata et al. study (2003); mean diabetes knowledge score of $68.3+/-16.1$ for the "DM-positive" group in Turkey according to Gunay et al. study (2006).

In a study by Al Shafaee et al. (2008), knowledge about diabetes was suboptimal. The percentages of correct responses to questions on diabetes definition, classical symptoms, and complications were $46.5 \%, 57.0 \%$, and $55.1 \%$, respectively. Only $29.5 \%, 20.8 \%$, and $16.9 \%$ identified obesity, physical inactivity, and positive family history.

On the other hand, our adherence score according to the MMAS was 6, which is less than that in the study of Al-Qazaz et al. (2011) in Malaysia, which reported a score of 6.5 (4.757.75) which means we have better adherence than Malaysia.

Our findings did not show significant correlations between the socio-demographic variables and knowledge, adherence, or control of diabetes, while it was shown in other studies, He and Wharrad (2007) and Tan and Magarey (2008) in which age and low education were predictors of lower knowledge (He and Wharrad, 2007; Tan and Magarey, 2008). This is presumptive because of the low level of knowledge about diabetes in our group of patients.

Finally, the number of medications used did not correlate to HbA1C control in our study in contrast to the study of Al-Qazaz et al. (2011).

The low knowledge, low adherence, and HbAlc levels rise many questions that need to be better interpreted, it could be due to cultural factors or due to depression in Jordanian diabetics that reaches 19.7\% according to AL-Amer et al. 2011 (2011) 
meaning, this may be underestimating the emotional distress levels in the diabetics knowing that depression and emotional distress affects adherence and self-care as shown in the study of Siguroardóttir (2005)

Other reasons may include social desirability bias. It is reasonable that some patients have biased answers while trying to follow the more socially desirable option rather than their actual behavior. The requirements for the daily management of DM in Jordan are paid by the Social Security except for the glucose stick and glucose monitoring device which are increasingly less affordable for patients of lower social status as well as the lack of healthy diet.Findings from this study should be interpreted with scrutiny. Our study had high percent of patients who refused to participate in the study (53 out of 550), which might be due to the fact that the majority of our patients had primary education and elderly (Table 1), and these categories are usually more reluctant to participate in clinical research because of lack of interest and knowledge about its benefit (Arfken et al., 2011). However, the study was still powered (see sample size calculations); it was conducted in patients admitted to clinics of one hospital (JUH) and usually, these patients are offered some sort of nonsystematic education. Therefore, the baseline knowledge that patients might have had could bias our results. In addition, and under these considerations, findings might not be generalizable to the whole Jordanian Diabetic population, Moreover, the cross-sectional nature of this study does not establish causality, but rather gives us a clue on the relationship between knowledge and adherence. Accordingly, future studies should evaluate knowledge in a multicenter setting all over the kingdom, to have more generalizable results as well as examine the effect of education on knowledge and, hence adherence, in a longitudinal interventional manner.

\section{CONCLUSION}

The data of the present study showed a moderate level of diabetes knowledge among study participants compared with other studies and less adherence scores to diabetes medications. No correlations were identified between glycemic control and socio-demographic variables with knowledge or adherence to medications. This motivates us to take more drastic action in education for the whole population to do a healthier lifestyle and to establish a health prioritize culture.

\section{REFERENCES}

Ajlouni K, Jaddou H, Batiha A. Diabetes and impaired glucose tolerance in Jordan: prevalence and associated factors. J Intern Med, 1998; 244:317-23.

Ajlouni K, Khader Y, Batieha A, Ajlouni H, EL-Khateeb M. An increase prevalence of diabetes mellitus in Jordan for over ten years. J Diabetes Complications, 2008; 22:317-24.

Al-Amer R, Sobeh M, Zayed A, Al-domi H. Depression among adults with diabetes in Jordan: risk factors and relationship to blood sugar control. J Diabetes Complications, 2011; 25:247-52.

Al Shafaee M, Al-Shukaili S, Rizvi S, Al Farsi Y, Khan M, Ganguly S, Afifi M, Al Adawi S. Knowledge and perceptions of diabetes in a semi-urban Omani population. BMC Public Health, 2008; 8(1):249.

Alsous M, Abed Jalil M, Odeh M, AL Kurdi R, Alnan M. Public knowledge, attitudes and practices towards diabetes mellitus: a crosssectional study from Jordan. PLoS One, 2019; 14(3). doi:10.1371/journal. pone. 0214479
Al-Qazaz H, Sulaiman S, Hassali M, Shafie A, Sundram S, Al-Nuri R, Saleem F. Diabetes knowledge, medication adherence and glycemic control among patients with type 2 diabetes. Int J Clin Pharm, 2011; 33(6):1028-35.

American Diabetes Association. Economic costs of diabetes in the U.S. in 2007. Diabetes Care, 2008; 31:596-615.

American Diabetes Association. Standards of medical care in diabetes. Diabetes Care, 2010; 33(Suppl 1):S11-61. Erratum in: Diabetes Care, $2010 ; 33: 692$.

Angeles A, Carbajal N, Allen B, Zamora S, Lazcano E. Gender, body mass index and sociodemographic variables associated with knowledge about type 2 diabetes mellitus among 13293 Mexican students. Acta Diabetol, 2005;42(1):36-45.

Arfken C, Balon R. Declining participation in research studies. Psychother Psychosom, 2011; 80(6):325-8. doi:10.1159/000324795

Berikai P, Meyer PM, Kazlauskaite R, Savoy B, Kozik K, Fogelfeld L. Gain in patients' knowledge of diabetes management targets is associated with better glycemic control. Diabetes Care, 2007; 30:1587-9.

Briesacher B, Andrade S, Fouayzi H, Chan K. Comparison of drug adherence rates among patients with seven different medical conditions. Pharmacotherapy, 2008; 28(4):437-43.

Brown DW, Mokdad AH, Walke H, As'ad M, Al-Nsour M, Zindah M, Arqoob K, Belbeisi A. Projected burden of chronic, noncommunicable diseases in Jordan. [letter]. Prev Chronic Dis, 2009; 6(2), A78. Available via http://www.cdc.gov/pcd/issues/2009/apr/ 08_0162.htm (Accessed April 2009).

Bruce D, Davis W, Cull C, Davis T. Diabetes education and knowledge in patients with type 2 diabetes from the community: the Fremantle diabetes study. J Diabetes Complications, 2003; 17(2):82-9.

Coffey JT, Brandle M, Zhou H, Marriott D, Burke R, Tabael BP, Englelgau MM, Kaplan RM, Herman WH. Valuing health-related quality of life in diabetes. Diabetes Care, 2002; 25, 2238-43.

El-Qudah J. Dietary knowledge among female diabetic patients in Amman, Jordan. Curr Res Nutr Food Sci, 2016; 4(2):107-13. doi:10.12944/CRNFSJ.4.2.04

Fitzgerald JT, Funnell MM, Hess GE, Barr PA, Anderson RM, Hiss RG, Davis WK. The reliability and validity of a brief diabetes knowledge test. Diabetes Care, 1998; 21(5):706-10.

Funnell M, Brown T, Childs B, Haas L, Hosey G, Jensen B, Maryniuk M, Peyrot M, Piette JD, Reader D, Siminerio LM, Weinger K, Weiss MA. National standards for diabetes self-management education. Diabetes Care, 2007; 30(6):1630-7.

Gonen B, Rochman H, Rubenstein A, Tanega S, Horwitz D Haemoglobin A1 An indicator of the metabolic control of diabetic patients. Lancet, 1977; 310(8041):734-7.

Gunay T, Ulusel B, Velipasaoglu S, Unal B, Ucku R, Ozgener N. Factors affecting adult knowledge of diabetes in Narlidere Health District, Turkey. Acta Diabetol, 2006; 43(4):142-7.

Hartz A, Kent S, James P, Xu Y, Kelly M, Daly J. Factors that influence improvement for patients with poorly controlled type 2 diabetes. Diabetes Res Clin Pract, 2006; 74:227-32.

He X, Wharrad H. Diabetes knowledge and glycemic controlamong Chinese people with type 2 diabetes. Int Nurs Rev, 2007; 54(3):280-7.

Hirai FE, Moss SE, Klein BE, Klein R. Relationship of glycemic control, exogenous insulin, and C-peptide levels to ischemic heart disease mortality over a 16-year period in people with older-onset diabetes: the Wisconsin Epidemiologic Study of Diabetic Retinopathy (WESDR). Diabetes Care, 2008; 31:493-7.

International Diabetes Federation. The diabetes atlas. 3rd edition, International Diabetes Federation, Brussels, Belgium, 2006. Available via http://www.idf.org/diabetesatlas/diabetes (Accessed April 2019).

International Diabetes Federation. The diabetes atlas. 8th edition, International Diabetes Federation, Brussels, Belgium, 2017. Available via http://www.idf.org/aboutdiabetes/what-is-diabetes/facts-figures.html (Accessed April 2019) 
Ishimura E, Okuno S, Kono K, Fujino-Kato Y, Maeno Y, Kagitani S, Tsuboniwa N, Nagasue K, Maekawa K, Yamakawa T, Inaba M, Nishizawa Y. Glycemic control and survival of diabetic hemodialysis patients - importance of lower hemoglobin A1C levels. Diabetes Res Clin Pract, 2009; 83:320-6.

Jacobsen N, Jensen H, Lund-Andersen H, Goldschmidt E. Is poor glycaemic control in diabetic patients a risk factor of myopia? Acta Ophthalmol, 2008; 86:510-4.

Jaffe JR, Nag SS, Landsman PB, Alexander CM. Reassessment of cardiovascular risk in diabetes. Curr Opin Lipidol, 2008; 17:644-52.

Krapek K, King K, Warren S, George K, Caputo D, Mihelich K, Holst EM, Nichol MB, Shi SG, Livengood KB, Walden S, Lubowski TJ. Medication adherence and associated hemoglobin A1c in type 2 diabetes. Ann Pharmacother, 2004; 38(9):1357-62.

Krousel-Wood M, Islam T, Webber L, Re RN, Morisky D, Muntner P. New medication adherence scale versus pharmacy fill rates in seniors with hypertension. Am J Manag Care, 2009; 15(1):59-66.

McClean M, McElnay J, Andrews W. The association of psychosocial and diabetes factors to diabetes knowledge. Int J Pharm Pract, 2001; 9:R9.

Mickey R, Greenland S. The impact of confounder selection criteria on effect estimation. Am J Epidemiol, 1989; 129(1):125.

Morisky D, Ang A, Krousel-Wood M, Ward H. Predictive validity of a medication adherence measure in an outpatient setting. J Clin Hypertens, 2008; 10(5):348-54.

Murata G, Shah J, Adam K, Wendel CS, Bokhari SU, Solvas PA, Hoffman RM, Duckworth WC. Factors affecting diabetes knowledge in type 2 diabetic veterans. Diabetologia, 2003; 46(8):1170-8.

Murugesan N, Snehalatha C, Shobhana R, Roglic G, Ramachandran A. Awareness about diabetes and its complications in the general and diabetic population in a city in southern India. Diabetes Res Clin Pract, 2007; 77(3):433-7.

Norris SL, Lau J, Smith SJ, Schmid CH, Engelgau MM. Selfmanagement education for adults with type 2 diabetes: a meta-analysis of the effect on glycemic control. Diabetes Care, 2002; 25:1159-71.

Panja S, Starr B, Colleran KM. Patient knowledge improves glycemic control: is it time to go back to the classroom? J Investig Med, 2005; 53:264-6.

Rhee MK, Slocum W, Ziemer DC, Culler SD, Cook CB, ElKebbi IM, Gallina DL, Barnes C, Phillips LS. Patient adherence improves glycemic control. Diabetes Educ, 2005; 31(2):240-50.

Sacks D, Bruns D, Goldstein D, Maclaren N, McDonald J, Parrott M. Guidelines and recommendations for laboratory analysis in the diagnosis and management of diabetes mellitus. Clin Chem, 2002; 48(3):436-72.

Siddiqui AA, Maddur H, Naik S, Cryer B. The association of elevated $\mathrm{HbA} 1 \mathrm{c}$ on the behavior of adenomatous polyps in patients with type-II diabetes mellitus. Dig Dis Sci, 2008; 53:1042-7.
Siguroardóttir K. 'Self-care in diabetes: Model of factors affecting self-care'. J Clin Nurs, 2005; 14(3):301-14. doi:10.1111/j.13652702.2004.01043.x

Simpson SH, Eurich DT, Majumdar SR, Padwal RS, Tsuyuki RT, Varney J, Johnson JA. A meta-analysis of the association between adherence to drug therapy and mortality. Br Med J, 2006; 333(7557):18-9.

Sratton IM, Adler AI, Neil HA, Matthews DR, Manley SE, Cull CA, Hadden D, Turner R, Holman RR. Association of glycaemia with macrovascular and microvascular complications of type 2 diabetes (UKPDS 35): prospective observational study. Br Med J, 2000; 321, 405-12.

Tan M, Magarey J. Self-care practices of Malaysian adults with diabetes and sub-optimal glycaemic control. Patient Educ Couns, 2008; 72(2):252-67.

Tesfaye S, Chaturvedi N, Eaton SE, Ward JD, Manes C, IonescuTirgoviste C, Witte DR, Fuller JH. EURODIAB Prospective Complications Study Group: Vascular risk factors and diabetic neuropathy. N Engl J Med, 2005; 352:341-50.

Tka'c I. Effect of intensive glycemic control on cardiovascular outcomes and all-cause mortality in type 2 diabetes: overview and metaanalysis of five trials. Diabetes Res Clin Pract, 2009; 86(Suppl 1): S57-62

Wild S, Roglic G, Green A, Sicree R, King H. Global prevalence of diabetes: estimates for the year 2000 and projections for 2030. Diabetes Care, 2004; 27(5):1047-53.

Zerriouh F, Khader Y. Diabetes in Jordan: prevalence, trend, awareness and control. IPROCEEDINGS, 2018; 4(1):e10565. doi:10.2196/10565

Zindah M, Belbeisi A, Walke H, Mokdad AH. Obesity and diabetes in Jordan: findings from the Behavioral Risk Factors Surveillance System. Prev Chronic Dis, 2005; 5(1). Available via http://www.cdc.gov/ pcd/issues/2008/jan/06_0172.htm.Accessed March 2009.

\section{How to cite this article:}

Madae'en S, Elayeh E, Akour A, AlQhaiwi T, Shaggour B, Madain R. Diabetes knowledge, medication adherence, and glycemic control among diabetic patients: A cross-sectional study in Jordan. J Appl Pharm Sci, 2020; 10(04):041-046. 